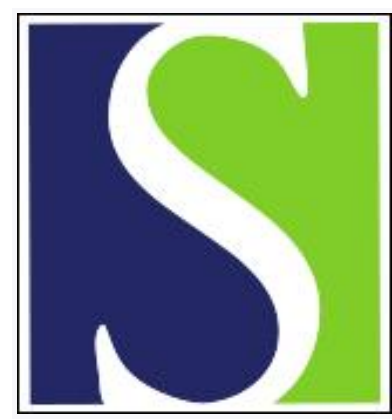

Scand J Work Environ Health 2007;33(4):293-303

https://doi.org/10.5271/sjweh.1146

Issue date: 31 Aug 2007

Parental occupational exposure to pesticides and the risk of childhood leukemia in Costa Rica

by Monge P, Wesseling C, Guardado J, Lundberg I, Ahlbom A, Cantor KP, Weiderpass $E$, Partanen T

Affiliation: Central American Institute for Studies on Toxic Substances (IRET), Universidad Nacional, PO Box 86-3000, Heredia, Costa Rica. pmonge@una.ac.cr

Key terms: cancer epidemiology; case-control study; child; childhood cancer; childhood leukemia; Costa Rica; developing country; fetal exposure; parental occupational exposure; pesticide; pregnancy; reproductive effect; risk; tropics

This article in PubMed: www.ncbi.nlm.nih.gov/pubmed/17717622 


\title{
Parental occupational exposure to pesticides and the risk of childhood leukemia in Costa Rica
}

\author{
by Patricia Monge, PhD, ${ }^{1,2}$ Catharina Wesseling, PhD, ${ }^{1,2}$ Jorge Guardado, LicComp, ${ }^{1}$ Ingvar Lundberg, \\ PhD, ${ }^{2,3}$ Anders Ahlbom, PhD, ${ }^{4}$ Kenneth P Cantor, PhD, ${ }^{5}$ Elisabete Weiderpass, PhD, ${ }^{6,7}$ Timo Partanen, PhD ${ }^{1}$
}

\begin{abstract}
Monge P, Wesseling C, Guardado J, Lundberg I, Ahlbom A, Cantor KP, Weiderpass E, Partanen T. Parental occupational exposure to pesticides and risk of childhood leukemia in Costa Rica. Scand J Work Environ Health 2007;33(4):293-303.
\end{abstract}

Objectives Parental exposure to pesticides and the risk of leukemia in offspring were examined in a population-based case-control study in Costa Rica.

Methods All cases of childhood leukemia (N=334), in 1995-2000, were identified at the Cancer Registry and the Children's Hospital. Population controls $(\mathrm{N}=579)$ were drawn from the National Birth Registry. Interviews of parents were conducted using conventional and icon-based calendar forms. An exposure model was constructed for 25 pesticides in five time periods.

Results Mothers' exposures to any pesticides during the year before conception and during the first and second trimesters were associated with the risk [odds ratio (OR) 2.4, 95\% confidence interval (95\% CI) 1.0-5.9; OR 22, 95\% CI 2.8-171.5; OR 4.5, 95\% CI 1.4-14.7, respectively] and during anytime (OR 2.2, 95\% CI 1.0-4.8). An association was found for fathers' exposures to any pesticides during the second trimester (OR 1.5, 95\% CI 1.0-2.3). An increased risk with respect to organophosphates was found for mothers during the first trimester (OR 3.5, 95\% CI $1.0-12.2$ ) and for fathers during the year before conception and the first trimester (OR 1.5, 95\% CI 1.0-2.2 and OR $1.6,95 \%$ CI 1.0-2.6, respectively), and benzimidazoles during the first, second, and third trimesters of pregnancy (OR 2.2, 95\% CI 1.0-4.4; OR 2.2, 95\% CI 1.0-5.0; OR 2.2, 95\% CI 1.0-5.2, respectively). There was a suggestion of an exposure-response gradient for fathers as regards picloram, benomyl, and paraquat. Age at diagnosis was positively associated with fathers' exposures and inversely associated with mothers' exposures.

Conclusions The results suggest that parental exposure to certain pesticides may increase the risk of leukemia in offspring.

Key terms cancer epidemiology; case-control study; childhood cancer; children; developing country; fetal exposure; pregnancy; reproductive effect; tropics.

Leukemias are the most common childhood cancers (1, 2), and their etiology is not well understood. Known or suspected general risk factors include male gender, age 1-4 years, particular genetic polymorphisms, ethnicity (Caucasian), high socioeconomic status, small families, low birthweight, and chemical and physical risk factors such as ionizing radiation, electromagnetic fields, chemical agents, dusts, fumes, spores, drugs and infections $(1,2)$.

Environmental exposures during development and childhood may place children at a higher leukemia risk than adults who receive such exposures later in life, due to different physical dimensions, less mature immune systems, unique diets, and metabolic characteristics $(3,4)$. Parental exposures to occupational hazards may contribute to the risk of leukemia or other cancers in offspring through damage to germ cells of either parent prior to pregnancy; intrauterine and early extrauterine exposure via maternal or paternal exposure to toxic compounds and their metabolites through transplacental transmission during gestation; or directly through breast

1 Central American Institute for Studies on Toxic Substances, Universidad Nacional, Heredia, Costa Rica.

2 Department of Public Health Sciences, Karolinska Institutet, Stockholm, Sweden.

3 National Institute for Working Life, Stockholm, Sweden.

4 National Institute of Environmental Medicine, Karolinska Institutet, Stockholm, Sweden.

5 Division of Cancer Epidemiology and Genetics, National Cancer Institute, Bethesda, MD, USA.

6 Department of Medical Epidemiology and Biostatistics, Karolinska Institutet, Stockholm, Sweden.

7 Cancer Registry of Norway, Oslo, Norway.

Reprint requests to: Dr P Monge, Central American Institute for Studies on Toxic Substances (IRET), Universidad Nacional, PO Box 86-3000, Heredia, Costa Rica. [E-mail: pmonge@ una.ac.cr] 
feeding, take-home exposure through contaminated person(s) or workclothes during the postnatal period (5-11). Bone marrow originates from the mesoderm, and its development occurs at the end of the first trimester of pregnancy. Exposure to teratogens during this trimester could sensitize embryos to problems in development, including childhood leukemia. Radiation during the first trimester has been found to be associated with higher risks of leukemia in children $(12,13)$.

An increased risk of childhood leukemia has been found to be associated with occupational paternal exposure to pesticides prior to and during pregnancy $(8,14-16)$ and parents' pesticide exposures at home or in gardens $(8$, 17-19). Pesticides associated with childhood leukemia include chlordane, dichlorvos, monomethyldithiocarbamate (metam sodium), propoxur, and dicofol (20-23).

The median incidence of childhood leukemias for 58 populations with cancer registry-based data for the 1990s was 45 (range 25-64) per million person-years. Costa Rica ranks third, with a rate of 63 per million, close to the 64 per million for Latin populations in Los Angeles (24). To date, no etiologic studies have been conducted in Costa Rica.

Agriculture, an important economic activity in Costa Rica, is associated with excessive and inappropriate use of pesticides (25). An annual average of $2.5 \mathrm{~kg}$ of active pesticide ingredient per inhabitant was estimated for the year 1996, compared with $0.7 \mathrm{~kg}$ in the Netherlands, for example, which represents a high European rate (26). Several pesticides that have been linked to childhood leukemia are in widespread use in Costa Rica. Propoxur is used in commercial domestic pest control products, and metam sodium and dicofol in ornamental plants and fruit growing, among other crops. Dichlorvos is used for crops, as well as for livestock.

Most agricultural workers experience complex exposure patterns to pesticides over time, the result being serious methodological limitations in many studies addressing pesticide exposures and childhood cancer, calling for improved exposure assessment with regard to chemical type and timing (7, 23, 27-29). With this need in mind, we conducted a population-based case-control study to evaluate associations between parental occupational exposure to pesticides and the risk of leukemia in offspring.

\section{Study population and methods}

\section{Ascertainment of cases and controls}

All cases of childhood leukemia (ages 0-14 years at diagnosis, $\mathrm{N}=334$ ) diagnosed in Costa Rica in 1995-2000 were identified at the Cancer Registry and the Children's Hospital of Costa Rica [International Classification
Diseases (ICD) 0-1]. Population controls $(\mathrm{N}=579)$, frequency matched to the cases by birth year, were drawn from the National Birth Registry, with the use of computerized random selection. The number of controls was chosen using cost-efficiency considerations (30). As Costa Rica uses landmarks to indicate addresses instead of street names and house numbers, we established a procedure to increase the likelihood of locating families while maintaining randomness and allowing for neighborhood replacement of nontraceable controls. Addresses and sometimes telephone numbers of the cases were obtained from files of the National Children's Hospital. In most cases, this information was adequate for tracing the family. When information was inadequate, we used databases of the local social security clinics. For the controls, the Birth Registry provided an address of the mother at the time of birth, which was sometimes complete but often restricted to a neighborhood. Using national electoral databases and local social security clinics, we were able to ascertain exact addresses for $62 \%$ of the controls. If the family was not located but information on a new address was available, we attempted to locate them at the new address. Otherwise, the control was replaced with a child of the same age living in the same neighborhood. If the address was untraceable, a control child of the same age was randomly selected from the archives of the health center in the neighborhood mentioned on the birth certificate. The overall response rate was $90 \%$ for the cases (19 refused to participate and 15 were not located) and $90.5 \%$ for the controls (55 refused to participate). Refusals were also substituted with controls in the same neighborhood. The effective number of cases was 300 ; that of controls was 579 (figure 1). Case diagnoses were extracted directly from Cancer Registry data and confirmed from files of the Children's Hospital. The study was approved by the Institutional Review Boards (IRB) of the Children's Hospital, Ministry of Health of Costa Rica, and the Karolinska Institutet in Sweden. All of the participants gave informed consent prior to the interviews.

We conducted face-to-face interviews with parents in 2001-2003 using an interview form to collect demographic data and data on known and suspected risk factors of childhood leukemia. Parents who were active in agriculture or livestock production during the assessment period completed an additional interview that utilized an icon-calendar form (ICF) (31). The response rate of ICF completion, based on sufficient and reasonably good quality data, was $90 \%$, with interviews of 83 cases and 139 control parents. After the data were cleaned and some parental questionnaires with incomplete data were excluded, data for 876 mothers and 762 fathers remained for the analyses (figure 1).

Out of the parents of the cases, $16.9 \%$ were active in agriculture; of the parents of the controls, $15.6 \%$ were 
active. With consideration for the small proportion of parents outside the active labor force, these figures are comparable with the $18.2 \%$ of the total labor force in agriculture in the national census of 2000 .

\section{Interview data on exposures and their determinants}

A conventional interview format was offered to both parents. It had three forms, one each for the mother, father and child (completed by either parent). The interview included the location of the family residence; education of the father and mother; smoking and substance abuse of the father and mother and diet of the mother; medical history of the mother, including vaccinations, the mother's X-rays and medications; pregnancy history; birth parameters; occupational, environmental and home pesticide exposures of both parents; occupational histories of the parents; and exposures of the father and mother to nonpesticide toxic agents. For those in agriculture, data on the parental use of pesticides, agricultural tasks, frequency of exposure (number of applications per month and hours per day), major determinants of pesticide exposure (task technology, personal protective equipment, field reentry, storing of pesticides, personal hygiene) were extracted with the ICF for the etiologically relevant period on a month-to-month basis (32). The relevant period was taken as the period from 12 months before conception until the diagnosis of cancer for the cases and until either the interview date or the age of 15 years for the controls, whichever occurred first.

The tasks were classified according to their estimated hazard $(0=$ no exposure; 4 = very high exposure). Tasks with no exposure (0) included coffee picking and organic agriculture. Tasks with a hazard value of 1 included tasks such as the watering of plants, tractor driving, and garden maintenance; those with a hazard value of 2 included fertilizing and defoliating; those with a hazard value of 3 included backpack application and the mixing of pesticides; and those with a hazard value of 4 included the application of pesticides with the hands (32).

Checklists of pesticides enhanced the interview as prompt lists. The pesticides selected for the checklists were based on a toxicity-based prioritization system designed for this study (33). The interview procedure has been described earlier in detail by Monge et al (31).

\section{Exposure assessment models}

The following 22 pesticides were identified as representing high priority on the basis of historical data on use and toxicity data on 2,4-dichlorophenoxyacetic acid (2,4-D), picloram, glyphosate, benomyl, chlorothalonil, paraquat, carbofuran, mancozeb, terbufos, methamidophos, deltamethrin, methomyl, triadimefon, fluazifop, captafol, lead arsenate, malathion, dichlorvos, diuron,

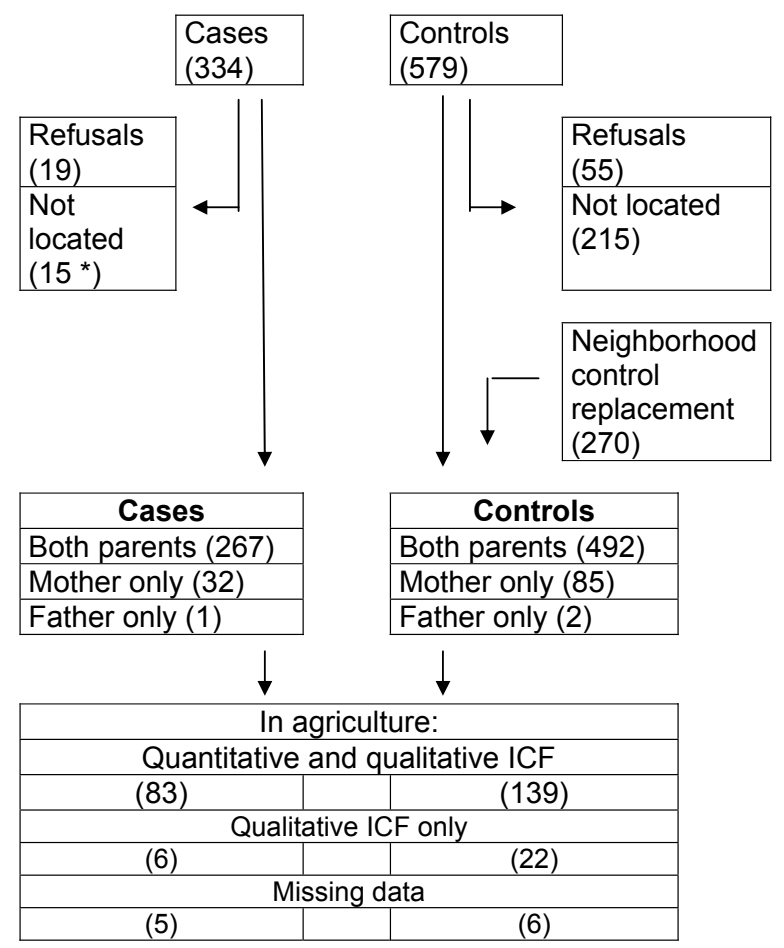

${ }^{*}$ For 8 cases, addresses were not located, 6 were living in other countries and 1 entire family had died.

Figure 1. Study structure. (ICF = icon-based calendar form)

oxamyl, quintozene, and aldrin (33). Cyproconazole, foxim, and fenamiphos were also included because their use was cited frequently by the participants. We constructed two exposure assessment models. A quantitative model combined ICF data with external data on the 25 prioritized pesticides for 14 crops, 21 calendar years, and 14 geographic regions. Since no measurement data were available, we used the application rates of pesticides from the external data as a basic component of the estimated exposure intensity. The application rates were obtained from a database of the Central American Institute for Studies in Toxic Substances-Universidad Nacional (IRET-UNA) that draws from databases of ministries, specialized crop offices, and agricultural bank loan records (34). Our experts, knowledgeable in pesticide use, checked and corrected these reports for any obvious inconsistencies. We converted the calendar time into individual time that had birth of the child as the zero time reference (30). Exposures were quasiquantitatively assessed for five time periods in the model that integrated personal data with the external data on pesticide, crop, and geographic region. The periods were the year before conception, the first trimester, the second trimester, the third trimester, and the first year of life of the child (32).

The qualitative model used binary (yes, no) indicators of occupational exposure in agricultural areas, derived from the ICF interview for 14 selected chemical 
groups of pesticides for all time period, in which any exposure to one of the compounds of the chemical group was sufficient to trigger "exposure": phenoxyacetic acids, organophosphates, organochlorines, carbamates, dithiocarbamates, pyrethroids, triazines, benzimidazoles, chlorinated phthalides, conazoles, copper compounds, arsenic compounds, chlorinated urea derivatives, and "other pesticides". The "other pesticides" group included pesticides not in any of the specific pesticide groups, the latter group consisting mainly of paraquat, chlorothalonil, and glyphosate.

All of the exposure assessment was done blinded as to the case-control status of the children.

\section{Statistical analysis}

Unconditional crude and adjusted logistic regression models were used to estimate the odds ratios (OR) and their $95 \%$ confidence intervals $(95 \% \mathrm{CI})$ as estimates of relative risk, separately for the five time periods. For preterm birth children, adjustment was applied for the conception date. Exposures were expressed as qualitative (yes, no), semiquantitative (unexposed, low exposure, high exposure) and quantitative metrics for specific pesticides and groups of pesticides. Sticking to the basic concept for confounding, we applied correlation-based selection of confounders instead of more-refined methods, expecting little difference in the results. Low correlations among the controls between variables of pesticide exposure and maternal age at conception, infectious disease of the child during the first year, the mother's and child's exposure to X-rays during pregnancy and first year of life, respectively, mother's tobacco and alcohol consumption during pregnancy, father's smoking, and history of newborn jaundice and vaccination of the child resulted in the inclusion only

Table 1. Odds ratios $(\mathrm{OR})$ and $95 \%$ confidence intervals $(95 \% \mathrm{Cl})$ for parents' exposure to prioritized pesticides (ie, those to which $>3$ cases had been exposed) - entries with $a \geq 1$ excess with a lower confidence limit of $<1$. ( $N=$ number of exposed cases)

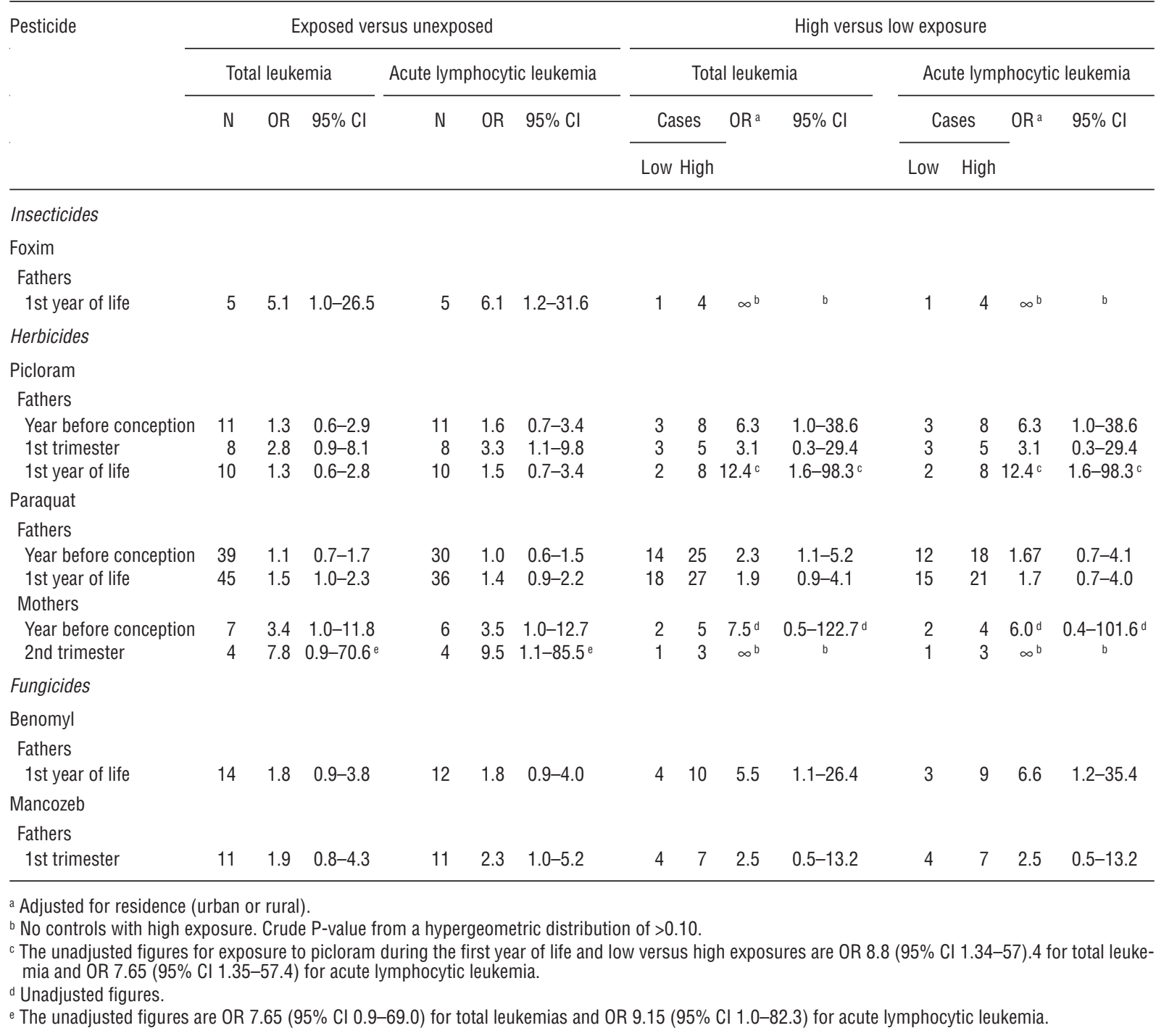


of the urban or rural residence in all of the logistic models controlling for unmeasured urban or rural risk factors. The mother's X-ray exposure during pregnancy was included because of its moderate correlation with phthalide exposure. The calculations were done with STATA Release 8.0 (Stata Corporation, College Station, TX, USA). The unexposed formed the reference group in all of the analyses, except for those between the high and low exposure groups (table 1 on page 296). The intratime-period correlation coefficients between pesticides were low (median absolute $|\mathrm{r}|=0.003$ ).

Table 2. Characteristics of the cases (total leukemia) and controls. (NOS = not otherwise specified)

\begin{tabular}{|c|c|c|}
\hline Characteristics & $\begin{array}{c}\text { Cases } \\
(\mathrm{N}=300) \\
(\%)\end{array}$ & $\begin{array}{c}\text { Controls } \\
(\mathrm{N}=579) \\
(\%)\end{array}$ \\
\hline \multicolumn{3}{|l|}{ Age at diagnosis } \\
\hline 0 years & 4.7 & . \\
\hline $1-4$ years & 43.3 & . \\
\hline $5-9$ years & 34.0 & . \\
\hline $10-14$ years & 18.0 & . \\
\hline \multicolumn{3}{|l|}{ Gender } \\
\hline Female & 44.3 & 50.8 \\
\hline Male & 55.7 & 49.2 \\
\hline \multicolumn{3}{|l|}{ Agricultural exposure to pesticides } \\
\hline Maternal & 4.3 & 2.2 \\
\hline Paternal & 24.6 & 22.2 \\
\hline \multicolumn{3}{|l|}{ Leukemia type } \\
\hline Acute lymphocytic leukemia & 84.0 & . \\
\hline Acute nonlymphocytic leukemia & 13.7 & . \\
\hline Other leukemias & 2.3 & . \\
\hline NOS & 0.3 & . \\
\hline \multicolumn{3}{|l|}{ Maternal age at conception } \\
\hline$<20$ years & 11.0 & 11.9 \\
\hline $20-24$ years & 33.0 & 30.1 \\
\hline $25-29$ years & 28.7 & 26.3 \\
\hline 30-34 years & 14.7 & 18.3 \\
\hline$\geq 35$ years & 11.7 & 13.0 \\
\hline Missing & 1.0 & 0.5 \\
\hline \multicolumn{3}{|l|}{ Maternal smoking during pregnancy } \\
\hline No & 92.3 & 94.6 \\
\hline Yes & 5.0 & 3.8 \\
\hline Missing & 2.7 & 1.6 \\
\hline \multicolumn{3}{|c|}{ Maternal alcohol intake during pregnancy } \\
\hline No & 95.1 & 94.8 \\
\hline Yes & 4.1 & 5.2 \\
\hline Missing & 1.0 & .. \\
\hline \multicolumn{3}{|l|}{ Maternal education } \\
\hline$\leq$ Primary school & 51.9 & 54.2 \\
\hline$>$ Primary to secondary school & 34.9 & 32.7 \\
\hline Technical or professional & 13.1 & 13.0 \\
\hline Missing & 3 & 2.1 \\
\hline \multicolumn{3}{|l|}{ Socioeconomic status of family a } \\
\hline Low & 29.7 & 22.3 \\
\hline Middle & 46.3 & 58.7 \\
\hline High & 10.3 & 10.0 \\
\hline Missing & 13.7 & 9.0 \\
\hline
\end{tabular}

${ }^{a}$ Assessed by interviewers with a form using various components-scored as low, medium, or high.

\section{Results}

The cases and controls were similar with respect to maternal age at conception, the proportion of parents exposed to pesticides, maternal smoking and alcohol consumption history during pregnancy, and maternal education. The cases were more often boys, and their families represented a slightly lower socioeconomic status. Acute lymphocytic leukemia represented $83.7 \%$ of the cases (table 2).

Altogether $13.9 \%$ of the parents of the cases $(24.6 \%$ of the fathers and $4.3 \%$ of the mothers) was ever exposed to any pesticides in work during the exposure assessment, while the percentage of the control parents was $11.5 \%$ (22.2\% for the fathers and $2.2 \%$ for the mothers).

Table 3 shows the odds ratios for the time windows for all of the pesticides and according to the following biocide category: insecticides, herbicides, and fungicides for the fathers and mothers. All of the odds ratios

Table 3. Odds ratios (OR) and 95\% confidence intervals (95\% CI) for parents' exposure to pesticides to which $>3$ cases had been exposed through biocide action-exposed versus unexposed. ( $\mathrm{N}=$ number of exposed cases)

\begin{tabular}{|c|c|c|c|c|c|c|}
\hline \multirow[t]{2}{*}{ Pesticide group } & \multicolumn{3}{|c|}{ Fathers } & \multicolumn{3}{|c|}{ Mothers } \\
\hline & N & $\mathrm{OR}^{\mathrm{a}}$ & $95 \% \mathrm{Cl}$ & $\mathrm{N}$ & $O \mathrm{R}^{\mathrm{a}}$ & $95 \% \mathrm{Cl}$ \\
\hline \multicolumn{7}{|l|}{ All pesticides } \\
\hline 1 year before conception & 64 & 1.2 & $0.9-1.8$ & 11 & 2.4 & $1.0-5.9$ \\
\hline 1st trimester of pregnan & 45 & 1.3 & $0.9-2.0$ & $11^{\mathrm{b}}$ & 22.0 & $2.8-171.5$ \\
\hline 2nd trimester of pregnancy & 45 & 1.5 & $1.0-2.3$ & 9 & 4.5 & $1.4-14.7$ \\
\hline 3rd trimester of pregnancy & 36 & 1.2 & $0.8-1.9$ & 9 & 2.2 & $0.8-5.8$ \\
\hline 1st year of life & 60 & 1.2 & $0.8-1.8$ & 10 & 2.0 & $0.8-4.8$ \\
\hline Anytime & 66 & 1.4 & $0.9-2.0$ & 13 & 2.2 & $1.0-4.8$ \\
\hline \multicolumn{7}{|l|}{ Insecticides } \\
\hline 1 year before conc & 41 & 1.4 & $0.9-2.1$ & 7 & 4.6 & $1.2-17.8$ \\
\hline 1st trimester of pregnancy & 20 & 1.2 & $0.7-2.1$ & \} 7 & & \\
\hline 2nd trimester of pregnancy & 21 & 1.2 & $0.7-2.0$ & \} & & \\
\hline 3rd trimester of pregnancy & 19 & 2.2 & $1.2-4.1$ & 7 & 3.4 & $1.0-11.8$ \\
\hline 1st year of life & 35 & 1.3 & $0.8-2.0$ & 6 & 2.9 & $0.8-10.5$ \\
\hline Anytime & 44 & 1.4 & $0.9-2.1$ & 9 & 3.0 & $1.0-8.4$ \\
\hline \multicolumn{7}{|l|}{ Herbicides } \\
\hline 1 year before conception & 53 & 1.2 & $0.8-1.7$ & 9 & 2.0 & $0.8-5.0$ \\
\hline 1st trimester of pregnancy & 35 & 1.4 & $0.9-2.1$ & 8 & 5.3 & $1.4-20$ \\
\hline 2nd trimester of pregnancy & 37 & 1.6 & $1.0-2.5$ & 8 & 5.3 & \\
\hline 3rd trimester of pregnancy & 31 & 1.3 & $0.8-2.1$ & 7 & 2.3 & $0.8-6.8$ \\
\hline 1st year of life & 53 & 1.3 & $0.8-1.9$ & 7 & 1.5 & $0.6-4.1$ \\
\hline Anytime & 60 & 1.4 & $0.9-2.0$ & 11 & 1.4 & $0.9-2.0$ \\
\hline \multicolumn{7}{|l|}{ Fungicides } \\
\hline 1 year before conception & 30 & 1.6 & $1.0-2.6$ & 4 & 7.7 & $0.9-69.7$ \\
\hline 1st trimester of pregnancy & 21 & 1.7 & $0.9-3.0$ & & & \\
\hline 2nd trimester of pregnancy & 16 & 1.2 & $0.6-2.3$ & 4 & & $0.9-10.6$ \\
\hline 3rd trimester of pregnancy & 16 & 1.7 & $0.9-3.4$ & 4 & 7.8 & $0.9-70.6$ \\
\hline 1st year of life & 28 & 1.5 & $0.9-2.5$ & 4 & 2.6 & $0.6-11.8$ \\
\hline Anytime & 36 & 1.9 & $1.1-3.0$ & 6 & 1.9 & $1.1-3.0$ \\
\hline
\end{tabular}

a Adjusted for residence (urban or rural).

b This OR is based on 11 exposed case mothers and 1 exposed control mother. The unadjusted OR was $21.6(95 \% \mathrm{Cl} 2.8-168.0)$. 
were above 1.0. The fathers' exposures showed an excess risk for all of the pesticides during the second trimester, insecticides during the third trimester, herbicides during second trimester, and fungicides in most of the time periods and anytime.

The odds ratios were, on the average, higher among the mothers than among the fathers; this finding indicated higher relative, but not necessarily higher absolute, excesses. The numbers of exposed mothers were smaller than those of the fathers. For the mothers, increased odds ratios were found for all exposure to pesticides for the year prior to conception, during the first and second trimester, and anytime; for exposure to insecticides during the year before conception, during the third trimester, and anytime; exposure to herbicides during the first and second trimesters (high OR 13.8 and 4.6, respectively); and exposures to fungicides anytime. Six mothers of cases were exposed to insecticides, and three were exposed fungicides, during the first trimester, with no exposed controls. These data were not quantifiable in the models, the odds ratio being infinite.

The results for acute lymphocytic leukemia were similar with the exception of exposure to insecticides for the fathers during the third trimester of pregnancy, which was not significant for acute lymphocytic leukemia.

Table 4 shows the odds ratios for exposure to pesticides according to the chemical group for the mothers with respect to total leukemia and acute lymphocytic leukemia. Increases were found for exposure to organophosphates in the first trimester for total leukemias and for exposure to organophosphates in the first and third trimester for acute lymphocytic leukemia. Exposure to "other" pesticides showed elevations for most of the time periods for total leukemias with respect to the year before conception and to the first, second, and third trimester and for all of the time windows for acute lymphocytic leukemia in respect to the year before conception, the first, second and third trimesters, and the first year of life. Other groups of pesticides had few, if any, exposed mothers.

Table 5 shows the associations, by chemical group, for the father's time period exposures with respect to total leukemias. Increased odds ratios were found for exposure to organophosphates during the year before conception and the first trimester and for benzimidazoles during the first, second, and third trimesters of pregnancy. The results for acute lymphocytic leukemia were similar (not tabulated).

Table 1 (on page 296) shows the associations of specific pesticides to total leukemia and acute lymphocytic leukemia. In the exposed versus unexposed analysis, the father's exposures to picloram and mancozeb during the first trimester of pregnancy and to foxim exposure during the first year of life of the child showed an association with acute lymphocytic leukemia. Foxim exposure of the father during the first year of life of the child was associated with total leukemia. The mother's exposures to paraquat during the year before conception and the second trimester of pregnancy were associated with acute lymphocytic leukemia. In the exposure-response analyses contrasting high and low exposure, excluding the unexposed, excesses were found for total leukemia

Table 4. Odds ratios (OR) and 95\% confidence intervals $(95 \% \mathrm{CI})$ for total leukemias and acute lymphocytic leukemia with respect to the mothers' exposure to pesticides to which $>3$ cases had been exposed, according to chemical group-exposed versus unexposed. ( $\mathrm{N}=$ number of exposed cases)

\begin{tabular}{|c|c|c|c|c|c|c|}
\hline \multirow[t]{2}{*}{ Time period } & \multicolumn{3}{|c|}{ Total leukemia } & \multicolumn{3}{|c|}{ Acute lymphocytic leukemia } \\
\hline & N & $O R^{a}$ & $95 \% \mathrm{Cl}$ & $\mathrm{N}$ & $O R^{a}$ & $95 \% \mathrm{Cl}$ \\
\hline \multicolumn{7}{|l|}{ Year before conception } \\
\hline Phenoxyacetic acids & 4 & 1.3 & $0.4-4.8$ & . & . & .. \\
\hline Organophosphates & 9 & 2.3 & $0.9-6.0$ & 8 & 2.5 & $0.9-6.7$ \\
\hline Paraquat, chlorothalonil, glyphosate and others & 11 & 2.8 & $1.1-7.2$ & 10 & 3.1 & $1.2-8.1$ \\
\hline \multicolumn{7}{|l|}{ 1st trimester } \\
\hline Organophosphates & 7 & 3.5 & $1.0-12.2$ & 6 & 3.7 & $1.0-13.1$ \\
\hline Paraquat, chlorothalonil, glyphosate and others & 9 & 3.7 & $1.2-11.1$ & 8 & 4.0 & $1.8-12.3$ \\
\hline \multicolumn{7}{|l|}{ 2nd trimester } \\
\hline Organophosphates & 5 & 2.5 & $0.7-9.5$ & 5 & 3.0 & $0.8-11.5$ \\
\hline Paraquat, chlorothalonil, glyphosate and others & 8 & 3.3 & $1.1-10.2$ & 8 & 4.0 & $1.3-12.5$ \\
\hline \multicolumn{7}{|l|}{ 3rd trimester } \\
\hline Organophosphates & 8 & 2.7 & $0.9-7.9$ & 8 & 3.3 & $1.1-9.6$ \\
\hline Paraquat, chlorothalonil, glyphosate and others & 9 & 3.7 & $1.2-11.2$ & 9 & 4.5 & $1.5-13.6$ \\
\hline \multicolumn{7}{|l|}{ 1st year of life } \\
\hline Organophosphates & 7 & 1.8 & $0.6-4.9$ & 6 & 1.8 & $0.6-5.4$ \\
\hline Paraquat, chlorothalonil, glyphosate and others & 9 & 2.1 & $0.8-5.3$ & 9 & 2.5 & $1.0-6.5$ \\
\hline
\end{tabular}

${ }^{a}$ Adjusted for residence (urban or rural). 
Table 5. Odds ratios (OR) and 95\% confidence intervals $(95 \% \mathrm{Cl})$ for total leukemia with respect to the fathers' exposure to pesticides to which $>3$ cases had been exposed, according to chemical group-exposed versus unexposed. ( $N=$ number of exposed cases)

\begin{tabular}{|c|c|c|c|c|c|c|c|c|c|c|c|c|c|c|c|}
\hline \multirow[t]{3}{*}{ Chemical group } & \multicolumn{15}{|c|}{ Total leukemia } \\
\hline & \multicolumn{3}{|c|}{ Year before conception } & \multicolumn{3}{|c|}{ 1st trimester } & \multicolumn{3}{|c|}{ 2nd trimester } & \multicolumn{3}{|c|}{ 3rd trimester } & \multicolumn{3}{|c|}{ First year of life } \\
\hline & $\mathrm{N}$ & $O R^{a}$ & $95 \% \mathrm{Cl}$ & N & $O R^{a}$ & $95 \% \mathrm{Cl}$ & N & $O R^{a}$ & $95 \% \mathrm{Cl}$ & $\mathrm{N}$ & $O R^{a}$ & $95 \% \mathrm{Cl}$ & N & $O R^{a}$ & $95 \% \mathrm{Cl}$ \\
\hline Phenoxyacetic acids & 28 & 1.0 & $0.6-1.6$ & 13 & 0.9 & $0.4-1.7$ & 15 & 0.9 & $0.5-1.7$ & 19 & 1.1 & $0.6-1.9$ & 29 & 1.1 & $0.7-1.7$ \\
\hline Organophosphates & 48 & 1.5 & $1.0-2.2$ & 33 & 1.6 & $1.0-2.6$ & 31 & 1.4 & $0.8-2.3$ & 30 & 1.5 & $0.9-2.5$ & 43 & 1.3 & $0.9-2.1$ \\
\hline Organochlorines & 7 & 1.0 & $0.4-2.5$ & 6 & 1.7 & $0.6-5.2$ & 5 & 1.2 & $0.4-3.8$ & 6 & 1.5 & $0.5-4.4$ & 7 & 1.3 & $0.5-3.3$ \\
\hline Carbamates & 14 & 1.3 & $0.6-2.5$ & 6 & 1.2 & $0.4-3.3$ & 8 & 1.6 & $0.6-4.1$ & 7 & 2.0 & $0.7-5.8$ & 11 & 1.1 & $0.5-2.5$ \\
\hline Dithiocarbamates & 16 & 1.4 & $0.7-2.7$ & 14 & 1.7 & $0.8-3.5$ & 11 & 1.2 & $0.6-2.7$ & 11 & 1.2 & $0.6-2.7$ & 15 & 1.5 & $0.7-2.9$ \\
\hline Pyrethroids & 10 & 1.2 & $0.5-2.6$ & 7 & 1.6 & $0.6-4.4$ & 7 & 1.4 & $0.5-3.8$ & 7 & 1.4 & $0.5-3.8$ & 8 & 0.9 & $0.4-2.0$ \\
\hline Triazines & 7 & 0.8 & $0.3-1.9$ & - & . & . & - & . & . & 4 & 1.0 & $0.3-3.4$ & 5 & 0.8 & $0.3-2.4$ \\
\hline Benzimidazoles & 19 & 1.8 & $0.9-3.4$ & 14 & 2.1 & $1.0-4.4$ & 13 & 2.2 & $1.0-5.0$ & 12 & 2.2 & $1.0-5.2$ & 16 & 1.7 & $0.9-3.5$ \\
\hline Chlorinated phthalides ${ }^{b}$ & 8 & 1.6 & $0.6-4.1$ & 5 & 2.5 & $0.7-9.4$ & 5 & 3.4 & $0.8-14$ & 4 & 2.6 & $0.6-11.8$ & 7 & 2.9 & $0.8-11$ \\
\hline Conazoles & 8 & 1.5 & $0.6-3.7$ & - & . & . & 4 & 2.0 & $0.5-8.1$ & 4 & 2.0 & $0.5-7.9$ & 9 & 1.5 & $0.6-3.6$ \\
\hline Copper & 11 & 1.0 & $0.5-2.1$ & 6 & 1.1 & $0.4-3.0$ & 4 & 0.7 & $0.2-2.1$ & 5 & 0.8 & $0.3-2.4$ & 8 & 0.7 & $0.3-1.7$ \\
\hline Others ${ }^{c}$ & 56 & 1.1 & $0.8-1.6$ & 38 & 1.1 & $0.7-1.7$ & 37 & 1.1 & $0.7-1.8$ & 36 & 1.1 & $0.7-1.8$ & 56 & 1.1 & $0.8-1.7$ \\
\hline
\end{tabular}

a Adjusted for residence (urban or rural).

${ }^{\mathrm{b}}$ Adjusted for exposure to X-rays during pregnancy, in the 2nd trimester, and in the first year of life.

c Mainly paraquat, chlorothalonil, and glyphosate.

among the fathers with respect to exposure to picloram during the year before conception and during the first year of life of the child (table 1 on page 296). Elevations for total leukemia and acute lymphocytic leukemia were also found for the fathers exposed to benomyl during the first year of life of the child, and an increased risk for total leukemia was found for those exposed to paraquat during the year before conception.

Associations according to the gender of the child were found for the fathers' exposures, to benomyl, mancozeb, and malathion for the boys and to picloram for the girls (table 6).

The analysis of age at diagnosis showed a tendency towards early diagnosis (1-5 years) for children whose mothers were exposed to any pesticides or groups of pesticides. The father's exposures appeared to be associated with later diagnosis in the life of the child, with the exception of exposure to fungicides (table 7). For the 14 cases diagnosed before their first birthday, the data were too few for analysis.

\section{Discussion}

We found an elevated risk of childhood leukemia in association with parents' occupational exposures to pesticides prior to and during pregnancy and over the first year of life. This finding is in accordance with the results of several studies $(8,14,16,17,19,22$, $23,35-38)$. The relative excesses in our study were strongest for the mothers and were found for the different types of biocides and several chemical groups. We found excesses specifically for picloram, benomyl,
Table 6. Significant (lower 95\% confidence limit $\geq 1.0$ ) excesses for either gender (unexposed versus exposed). ( $\mathrm{N}=$ number of exposed cases)

\begin{tabular}{|c|c|c|c|c|c|c|}
\hline \multirow[t]{2}{*}{ Pesticide } & \multicolumn{3}{|c|}{ Boys } & \multicolumn{3}{|c|}{ Girls } \\
\hline & $\mathrm{N}$ & $\mathrm{OR}^{\mathrm{a}}$ & $95 \% \mathrm{Cl}$ & $\mathrm{N}$ & $O R^{a}$ & $95 \% \mathrm{Cl}$ \\
\hline \multicolumn{7}{|l|}{ Total leukemia } \\
\hline \multicolumn{7}{|l|}{ Insecticides } \\
\hline \multicolumn{7}{|l|}{ Malathion, fathers } \\
\hline Year before conception & 5 & 8.5 & $1.1-74.1$ & 2 & 0.9 & $0.2-4.9$ \\
\hline \multicolumn{7}{|l|}{ Herbicides } \\
\hline \multicolumn{6}{|l|}{ Picloram, fathers } & $1.1-19.2$ \\
\hline \multicolumn{7}{|l|}{ Fungicides } \\
\hline \multicolumn{7}{|l|}{ Benomyl, fathers } \\
\hline Year before conception & 13 & 2.5 & $1.1-6.0$ & 4 & 0.9 & $0.3-2.8$ \\
\hline 1st year & 12 & 3.0 & $1.1-7.7$ & 2 & 0.5 & $0.1-2.6$ \\
\hline \multicolumn{7}{|c|}{ Acute lymphocytic leukemia } \\
\hline \multicolumn{7}{|l|}{ Insecticides } \\
\hline \multicolumn{7}{|l|}{ Malathion, fathers } \\
\hline Year before conception & 5 & 10.4 & $1.2-91.1$ & 1 & 0.5 & $0.1-4.8$ \\
\hline \multicolumn{7}{|l|}{ Herbicides } \\
\hline \multicolumn{7}{|l|}{ Picloram, fathers } \\
\hline 1st trimester & 3 & 1.9 & $0.38-9.8$ & 5 & 5.2 & $1.2-22.5$ \\
\hline 1st year of life & 3 & 0.7 & $0.18-2.7$ & 7 & 2.7 & $1.1-7.8$ \\
\hline \multicolumn{7}{|l|}{ Fungicides } \\
\hline \multicolumn{7}{|l|}{ Benomyl, fathers } \\
\hline Year before conception & 12 & 2.8 & $1.1-6.9$ & 3 & 0.9 & $0.3-2.8$ \\
\hline 1st year of life & 11 & 3.3 & $1.2-8.8$ & 1 & 0.3 & $0.1-2.5$ \\
\hline \multicolumn{7}{|l|}{ Mancozeb, fathers } \\
\hline 1st trimester & 9 & 3.1 & $1.1-9.0$ & 3 & 1.0 & $0.3-3.3$ \\
\hline
\end{tabular}

a Adjusted for residence (urban or rural).

foxim, paraquat, mancozeb, and malathion, compounds for which we did not find earlier data on humans with regard to childhood cancer. 
The odds ratios for maternal exposure tended to be higher than for paternal exposure. This difference was found for all pesticides pooled and exposure at anytime, before conception, and during the first and second trimesters of pregnancy; for exposure to insecticides any time, in the year before conception, and during the first and second trimesters; and for exposure to herbicides during the first and second trimesters of pregnancy. The odds ratios were similar between the mothers and fathers for exposure to fungicides any time, but, for the time periods, were considerably higher for the mothers, although with fewer exposed cases. With regard to

Table 7. Odds ratios (OR) and 95\% confidence intervals (95\% $\mathrm{Cl}$ ) for total leukemia and pesticide exposure by age at diagnosis. ( $N$ = number of exposed cases)

\begin{tabular}{|c|c|c|c|c|c|}
\hline \multirow[t]{3}{*}{ Parent } & \multicolumn{5}{|c|}{ Age at diagnosis ${ }^{\mathrm{a}}$} \\
\hline & \multicolumn{3}{|c|}{$1-5$ years } & \multicolumn{2}{|c|}{$6-15$ years } \\
\hline & $N$ & $\mathrm{OR}^{\mathrm{b}}$ & $95 \% \mathrm{Cl}$ & $\mathrm{NOR}$ & $95 \% \mathrm{Cl}$ \\
\hline \multicolumn{6}{|l|}{ Mothers } \\
\hline \multicolumn{6}{|l|}{ Total pesticides } \\
\hline 1 year before conception & 7 & 3.0 & $1.1-8.3$ & 42.0 & $0.6-6.6$ \\
\hline 1st trimester of pregnancy & & $27.6^{c} 3$ & $3.4-226.1^{\mathrm{c}}$ & $c 418.0^{\circ} 2$ & $2.0-162.2^{c}$ \\
\hline 2nd trimester of pregnancy & 6 & 5.8 & $1.6-21.1$ & 33.3 & $0.7-15.2$ \\
\hline 3rd trimester of pregnancy & 6 & 2.9 & $1.0-8.5$ & 31.6 & $0.4-6.4$ \\
\hline 1st year of life & 6 & 2.3 & $0.8-6.5$ & 41.8 & $0.5-5.8$ \\
\hline \multicolumn{6}{|l|}{ Fathers $^{d}$} \\
\hline \multicolumn{6}{|l|}{ Total pesticides } \\
\hline 1 year before conception & 26 & 0.8 & $0.5-1.3$ & 371.8 & $1.1-2.9$ \\
\hline ter of pregnancy & 20 & 0.9 & $0.5-1.6$ & 241.4 & $0.8-2.4$ \\
\hline 2nd trimester of pregnancy & 21 & 1.1 & $0.6-1.8$ & 241.6 & $0.9-2.6$ \\
\hline $3 r d t$ & 18 & 0.9 & $0.5-$ & 181.2 & $0.7-2.1$ \\
\hline 1st year of & 26 & 0.9 & $0.5-$ & 331.6 & 1.0 \\
\hline \multicolumn{6}{|l|}{ Herbicides } \\
\hline 1 year before conception & 23 & 0.9 & $0.5-1.5$ & 311.7 & $1.0-2.7$ \\
\hline nester of pregnancy & 16 & 1.0 & $0.6-1.9$ & 221.9 & $1.1-3.3$ \\
\hline 2nd trimester of pregnancy & 19 & 1.4 & $0.8-2.5$ & 222.1 & $1.2-3.6$ \\
\hline of pregnancy & 16 & 1.1 & & & \\
\hline 1st year of & 23 & 0.9 & $0.5-1.6$ & 311.8 & $1.1-3$ \\
\hline \multicolumn{6}{|l|}{ Fungicides } \\
\hline 1 year before conception & 20 & 2.0 & $1.1-3.6$ & 121.3 & $0.6-2.6$ \\
\hline 1st trimester of pregnancy & 13 & 1.9 & $1.0-3.9$ & 91.5 & $0.7-3.3$ \\
\hline 2nd tr & 12 & 1.7 & $0.8-3.5$ & 50.8 & $0.3-2.1$ \\
\hline regnancy & 11 & 2.2 & $1.0-4.8$ & 61.3 & $0.5-3.4$ \\
\hline 1st year of life & 16 & 1.6 & $0.9-3.1$ & 121.4 & $0.7-2.8$ \\
\hline \multicolumn{6}{|l|}{ Organophosphates } \\
\hline 1 year before conception & 23 & 1.3 & $0.8-2.2$ & 241.7 & $1.0-2.9$ \\
\hline 1st trimester of pregnancy & 12 & 1.0 & $0.5-2.0$ & 202.3 & $1.3-4.2$ \\
\hline 2nd trimester of pregnancy & 14 & 1.2 & $0.6-2.2$ & 161.7 & $0.9-3.1$ \\
\hline ter of pregnancy & 14 & 1.3 & $0.7-2.5$ & 151.7 & $0.9-3.2$ \\
\hline 1st year of life & 19 & 1.1 & $0.6-1.9$ & 231.7 & $1.0-2.9$ \\
\hline \multicolumn{6}{|l|}{ Paraquat } \\
\hline 1 year before conception & 14 & 0.7 & $0.4-1.3$ & 241.6 & $1.0-2.8$ \\
\hline 1st year of life & 12 & 1.1 & $0.6-2.0$ & 252.0 & $1.2-3.5$ \\
\hline \multicolumn{6}{|c|}{$\begin{array}{l}\text { Data for first-year diagnosis were insufficient. One mother and one father } \\
\text { of the } 14 \text { cases diagnosed during this year were exposed to any pesticides } \\
\text { during the exposure assessment period. } \\
{ }^{b} \text { Adjusted for residence (urban or rural). } \\
{ }^{\circ} \text { Unstable estimate due to the small number (1) of controls in each cat- } \\
\text { egory of age at diagnosis. } \\
\text { d Only sets with at least one } P(O R) \leq 0.05 \text {. }\end{array}$} \\
\hline
\end{tabular}

chemical groups of pesticides, organophosphates (for the first and third trimesters) and "other" pesticides (chlorothalonil, paraquat, and glyphosate) showed consistently higher odds ratios for the mothers than for the fathers. Benzimidazoles had a higher odds ratio for the fathers. For specific pesticides, the small number of exposed mothers precluded comparison. A stronger association between childhood leukemia and maternal exposure to pesticides compared with paternal exposure was also reported by Meinert et al (8). Our data are unclear as to whether exposures before and during pregnancy, as compared with exposures after birth, are more important, whereas Meinert et al (8) found that earlier exposures confer higher risk. Our data suggest that maternal exposures were associated with leukemias diagnosed early in life, while paternal exposures tended to be associated with later diagnoses (table 7).

Fathers' exposures showed an association with childhood leukemia for insecticides (third trimester), herbicides (second trimester), fungicides (anytime and the year before conception), organophosphates (before conception and during the first trimester of pregnancy), and benzimidazoles (anytime and during all three trimesters). The risk excess for paraquat exposure after birth was significant, as was that for mancozeb exposure during the first trimester of pregnancy (acute lymphocytic leukemia) and foxim exposure after birth and anytime. There was a suggestion of an exposure-response association for paraquat, picloram, and benomyl before conception and after birth (table 1). These results support the hypothesis that pesticides are etiologic factors for leukemia, but the findings were not informative about the exposure routes or mechanisms $(39,40)$. With regard to the gender of the child, benomyl exposure during the year before conception and during the first year of life and malathion exposure during the year before conception showed elevations among the boys, whereas picloram exposures during the first trimester and after birth were associated with acute lymphocytic leukemia among the girls. The reasons for these differences are not apparent.

All of the six pesticides (picloram, paraquat, mancozeb, benomyl, malathion, and foxim) that were associated with a risk of childhood leukemia in our data have been previously found to be associated with chromosome aberrations or mutagenicity [41-45; unpublished data: US Environmental Protection Agency, Office of Drinking Water. Paraquat Health Advisory (draft)]. However, with the exception of malathion, for which detectable mutations were associated with its exposure in three different types of human culture cells, including white blood cells and lymph cells $(42,43)$, the data are inconsistent and inconclusive (41-45). Benomyl and mancozeb have been found to be associated with cancer in humans $(46,47)$, but not with leukemia. 
The mothers' and fathers' exposures were correlated because they often shared the same agricultural setting, and possibly due to similarity in the pattern of responding during the interview. The correlation coefficient between the mothers and fathers, calculated for odds ratios for insecticides, herbicides and fungicides in the five time periods (table 3 ), was moderately low (0.32). It remains uncertain whether the case mothers and fathers would recall their job details (which were the basis for the assessment of their exposures) better than the controls did. This uncertainty leaves room for a possible positive information bias. Exposure assessment was blinded to the case-control status of the children.

Exposures were correlated between the time periods (ie, those exposed during one time period were likely to be exposed also during other time periods). Thus the correlation coefficients between the father's exposure (binary yes, no) to organophosphate pesticides during the five time periods ranged from 0.66 to 0.85 ; those for the father's exposure to phenoxyacetic herbicides were $0.57-0.84$; those for the father's exposure to paraquat were $0.55-0.72$; and those for the mother's exposure to organophosphate pesticide were $0.60-0.82$.

As the causes of childhood leukemia are poorly known, there is little a priori basis for the selection and inclusion of confounders in analytic models. Using a list of preselected possible confounders, we calculated correlation coefficients for the controls between exposure to these possible confounders and pesticide exposures. This procedure allowed us to prioritize the factors to be controlled in the logistic models (urban or rural residence in most of the models) and discard variables with low correlations (absolute maximum value $|\mathrm{r}|=0.17$ ) with the pesticide variables. We do believe that using other means of selecting confounders would have changed the results to a meaningful extent.

Both the cases and controls were selected from the general population. The procedure for selecting and locating the controls probably ensured the representation of the general infant and child population from which the cases were identified. The controls were replaced by age group and the place of residence of the original control. Thirty-four cases were not included in the study (19 refused to participate and 15 could not be located). The distribution of the year of diagnosis of the 34 cases not included in the study (19 refusals and 15 not located) was similar to that of the cases in the analysis. The addresses of the unincluded cases were urban for 58\% and rural or semirural for $42 \%$; these percentages are similar to those of the addresses of the case population. There was no information available on whether the 14 rural or semirural cases were exposed differently than the cases included in the analysis. Misclassification of exposure due to interview-based assessment was possible in our study. Nevertheless, our model for exposure assessment involved a "prompt list" of pesticides, which should have increased the sensitivity of the exposure assessment but may have decreased the specificity. These effects were probably nondifferential between the cases and controls and would have tended to bias the odds ratios towards unity. The only data we have on the original control children who were replaced because of incomplete addresses were geographic location and age, both of which were retained in the replacement of the control children.

We did not adjust for multiple comparisons, as we were generally not dealing with joint or overall null hypotheses (48).

After three decades of research, the role of parental occupational exposures in the development of childhood leukemia remains unclear (11). Pediatric leukemias have multifactorial etiologies involving both human genetics and interactions between environmental factors (39). Previous studies with other populations have reported associations of childhood leukemia with environmental exposure to pesticides. Children of farmers and farm workers are exposed to agricultural chemicals in utero through transplacental transmission during gestation and also during the postnatal period through diverse pathways. They live or work on farms with their parents and come into contact with agricultural chemicals through direct contact with plants, soil, water, air, and stored pesticides through their parents' take-home exposures, via direct physical contact with their parents through inhalation of the parents' breath, workclothes, and skin and via other routes (10).

Epidemiologic studies of pesticides and childhood leukemia have been reviewed earlier $(7,11,27)$. Some studies have investigated pesticide exposures of the child at home, in gardens, or on farms $(8,19,35-37)$. A variety of exposure assessment methods was used in these studies. Some used parental occupation as a surrogate for pesticide exposure $(14,17,29,35)$, others included interviews or self-reports $(8,19,36,49)$, and others used the inclusion in registers to represent exposure $(23,50,51)$. Some differentiated between maternal and paternal exposures $(8,14,35,36,52)$. Recommendations included improving exposure assessment methods, particularly for maternal exposure. Our exposure assessment included a sophisticated interview form to improve recall and a model for specific pesticides and chemical groups that incorporated aspects of time (frequency of use, length of application), application technique, and protective practices. We assessed exposures for fathers and mothers separately and integrated interview information and external data on time-, locality-, and cropspecific pesticide application practices $(31,32)$.

A prioritization system for specific pesticides based on toxicity and frequency of use was also used by Reynolds et al (23) in a case-control study of childhood 
leukemia using a geographic information system in the exposure assessment of the mothers during pregnancy on the basis of the distance of the home from exposure sources. They found excess risks for areas with high application volumes of metam sodium and dicofol. Exposures to these two pesticides were not assessed.

This report addresses sources of occupational exposure. The results concerning environmental and household exposures to pesticides will be reported separately, as those for other reported risk factors, such as radiation, organic solvents, medications, early infectious diseases in childhood, immunologic aspects, and genetic susceptibility. In conclusion, we found associations between occupational parental pesticide exposures and childhood leukemia in a developing country with heavy use of pesticides and a high rate of childhood leukemia.

We recommend the prevention of pesticide hazards, especially in the population stratum reproductively active and among children. The $\mathrm{C} 139$ convention of the International Labour Organization (ILO) concerning the prevention and control of occupational hazards caused by carcinogenic substances and agents was established in 1974, taking into account the relevant work of the World Health Organization (WHO) and the International Agency for Research on Cancer (IARC) regarding cancer research. The convention has been ratified by several countries, but not by Costa Rica. It establishes the following issues (i) periodic listing of carcinogenic substances that would be prohibited or made subject to authorization and control, (ii) replacement of carcinogenic substances, (iii) exposure minimization, (iv) appropriate system of records, (v) provision of information on dangers and protection to workers, (vi) appropriate medical examinations or biological or other tests for investigations, and (vii) codes of industrial or agricultural conduct. All of these measures are relevant in the prevention of childhood cancer through parental occupational exposures, such as carcinogenic pesticides.

\section{Acknowledgments}

This work was partially supported by the Research Department of the Swedish International Cooperation Agency SAREC/Sida, a grant from the International Scholar in Occupational and Environmental Health, Fogarty grant 5 D43 TW00642-07 from the University of Washington (Seattle, WA, USA), and the Intramural Program of the United States National Cancer Institute.

Special thanks go to Rocío Loría-Bolaños, Marianela Rojas, Rebeca Alvarado, Heidi Morales, Carolina Castillo Abdalla, Jenny Umaña, Gina Solano, Emilia González, Gabriela Rodríguez, and Emma Chacón who were responsible for the data collection and to Matthew
Keifer, Viria Bravo, Lawrence Engels, Clemens Ruepert, Igor Burstyn, Moniek Zuurbier, Ana Cecilia Rodríguez, and Patricia Stewart who helped during the different stages of this project. We thank also Tatiana Sánchez for her help with the drawings, Fabio Chaverri and Fernando Ramírez for their review of the external data on pesticide application used in the model, and Margarita Mena for her administrative support.

\section{References}

1. Little J. Epidemiology of childhood cancer. Lyon: International Agency for Research on Cancer (IARC); 1999. IARC scientific publications 149.

2. Parkin DM, Kramárová E, Draper GJ, Masuyer E, Michaelis $\mathrm{J}$, Neglia J, et al. International incidence of childhood cancer, vol II. Lyon: International Agency for Research on Cancer (IARC); 1998. IARC scientific publications 144.

3. Committee on Pesticides in the Diets of Infants and Children, National Research Council. Pesticides in the diets of infants and children. Washington (DC): National Academy Press; 1993.

4. Van Larebeke N, Birnbaum L, Boogaerts M, Bradke M, Davis DL, Demarini DM, et al. Unrecognized or potential risk factors for childhood cancer. Int J Occup Environ Health. 2005;11:199-201.

5. Shu XO, Stewart P, Wan-Quing W, Dehui H, Potter JD, Buckley JD, et at. Parental occupational exposure to hydrocarbons and risk of acute lymphocytic leukemia in offspring. Cancer Epidemiol Biomarkers Prev. 1999;8:783-91.

6. Savitz DA, Chen JH. Parental occupation and childhood cancer: review of epidemiological studies. Environ Health Perspect. 1990;88:325-37

7. Zahm SH, Ward MH. Pesticides and childhood cancer. Environ Health Perspect. 1998;106 Suppl 3: 909-25.

8. Meinert R, Schuz J, Keltsch U, Kaatsch P, Michaelis J. Leukemia and non-Hodgkin's lymphoma in childhood and exposure to pesticides: results of a register-based case control study in Germany. Am J Epidemiol. 2000;151:639-46.

9. Ries LAG, Smith MA, Gurney JG, Linet M, Tamra T, Young JL, et al, editors. Cancer incidence and survival among children and adolescents: United States SEER Program 1975-1995. Bethesda (MD): National Cancer Institute, SEER Program; 1999. NIH publication 99-4649.

10. Curl CL, Fenske R, Kissel JC, Shirai J, Moate T, Griffith W, et al. Evaluation of take-home organophosphorus pesticide exposure among agricultural workers and their children. Environ Health Perspect. 2002;110:787-92.

11. Buffler PA, Kwan ML, Reynolds P, Urayama K. Environmental and genetic risk factors for childhood leukemia: appraising the evidence. Cancer Invest. 2005;21:60-75.

12. John EM, Savitz DA, Sandler DP. Prenatal exposure to parents' smoking and childhood cancer. Am J Epidemiol. 1991;133(2):123-32

13. Doll R, Wakaford R. Risk of childhood cancer from fetal irradiation. Br J Radiol. 1997;70:130-9.

14. Shu XO, Gao YT, Brinton LA, Linet MS, Tu JT, Zheng W, Fraumeni JF Jr. A population-based case-control study of childhood leukemia in Shanghai. Cancer. 1988;62:635-44.

15. Infante-Rivard C, Labuda K, Krajinovic M, Sinnett D. Risk of 
childhood leukemia associated with exposure to pesticide and with gene polymorphism. Epidemiology. 1999;10:481-7.

16. Petridou E, Dessypris N. Maternal pesticide exposure and childhood leukemia. Epidemiol. 2000;11:230.

17. Lowengart RA, Peters JM, Cicioni C, Buckey J, Bernstein L, Preston-Martin S, et al. Childhood leukemia and parent's occupation an home exposures. J Natl Cancer Inst. 1987;79:3946.

18. Leiss JK, Savitz DA. Home pesticide use and childhood cancer: a case-control study. Am J Public Health. 1995;85(2):249_ 52.

19. Menegaux F, Baruchel A, Bertrand Y, Lescoeur B, Leverger G, Nelken B, et al. Household exposure to pesticides and risk of childhood leukaemia. Occup Environ Med. 2006;63:131-4.

20. Reeves JD. Household insecticide-associated blood dyscrasias in children. Am J Hematol Oncol. 1982;4:438-9

21. Infante PF, Epstein SS, Newton WA Jr. Blood dyscrasias and childhood tumors and exposure to chlordane and heptachlor. Scand J Work Environ Health. 1978;4:137-50.

22. Reeves JD. Household insecticide associated aplastic anaemia and acute leukaemia in children. Lancet. 1981;8;2:300-1.

23. Reynolds P, Von Behren J, Gunier R, Goldberg D, Harnly M, Hertz A. Agricultural pesticide use and childhood cancer in California. Epidemiology. 2005;16:93-100.

24. Monge P, Wesseling C, Rodríguez AC, Cantor K, Weiderpass E, Reutfors, et al. Childhood leukemia in Costa Rica, 1981-1996. Paediatr Perinatal Epidemiol. 2002;16:210-8.

25. Wesseling C, Aragón A, Castillo L, Corriols M, Chaverri F, de la Cruz E, et al. Hazardous pesticides in Central America. Int J Occup Environ Health. 2001;7:287-94

26. Chaverri F, Blanco J. Importaciones, formulación y uso de plaguicidas en Costa Rica [Imports, formulation and use of pesticidas in Costa Rica]. Heredia (Costa Rica): Universidad Nacional, Instituto Regional de Estudios en Sustancias Tóxicas: Editorial, Universidad Nacional; 2002.

27. Daniels JL, Olshan AF, Savitz DA. Pesticides and childhood cancers. Environ Health Perspect. 1997;105:1068-77.

28. Colt JS, Blair A. Parental occupational exposures and risk of childhood cancer. Environ Health Perspect. 1998;106 suppl 3:909-25.

29. Feychting M, Plato N, Nise G, Ahlbom A. Paternal occupational exposures and childhood cancer. Environ Health Perspect. 2001;109:193-6.

30. Miettinen OS. Theoretical epidemiology: principles of occurrence research in medicine. New York (NY): Wiley; 1985.

31. Monge P, Wesseling C, Engel L, Keifer M, Zuurbier M, Rojas $\mathrm{M}$, et al. An icon-based interview for the assessment of occupational pesticide exposure in a case-control study of childhood leukemia. Int J Occup Environ Health. 2004;10:72-8.

32. Monge P, Partanen T, Wesseling C, Bravo V, Ruepert C, Burstyn I. Assessment of pesticide exposure in the agricultural population of Costa Rica. Ann Occup Hyg. 2005;49(5):37584.

33. Valcke M, Chaverri F, Monge P, Bravo V, Partanen T, Wesseling C. Pesticide prioritization for a case-control study on childhood leukaemia in Costa Rica: a simple stepwise approach. Environ Res. 2005;97:335-47.

34. Wesseling C, Bravo V. Pesticide use on the main crops of Costa Rica 1970-2000: data for retrospective exposure assessment in epidemiologic studies: report to the US National Cancer Institute. Heredia (Costa Rica): Central American Institute for Studies on Toxic Substances (IRET), Universidad Nacional; 2002 .
35. Buckley JD, Robison LL, Swotinsky R, Garabrant DH, LeBeau M, Manchester P, et al. Occupational exposures of parents of children with acute nonlymphocytic leukemia: a report from the Children's Cancer Study Group. Cancer Res. 1989;49:4030-7.

36. Meinert R, Kaatasch P, Kaletsch U, Krummenauer F, Miesner A, Michaelis J. Childhood leukemia and exposure to pesticides: results of a case-control study in Northern Germany. Eur J Cancer. 1996;32A:1943-8.

37. Abadi-Korek, Stark B, Zaizov R, Shaham J. Parental occupational exposure and the risk of acute lymphoblastic leukemia in offspring in Israel. J Occup Environ Med. 2006;48:165-74.

38. Infante-Rivard C, Sinnet D. Preconceptional paternal exposure to pesticides and increased risk of childhood leukemia. Lancet. 1999;354:1819.

39. Greaves M. Childhood leukaemia. Br Med J. 2002;324:28387.

40. Alexander FE, Patheal SL, Biondi A, Brandalise S, Cabrera ME, Chan LC, et al. Transplacental chemical exposure and risk of infant leukemia with MLL gene fusion. Cancer Res. 2001;61:2542-6.

41. National Research Council. Drinking water and health, vol. 5. Washington (DC): Board on Toxicology and Environmental Health Hazards, Commission on Life Sciences, Safe Drinking Water Committee, National Academy Press; 1983.

42. US Environmental Protection Agency. Memorandum from the Office of Pesticides and Toxic Substances to Office of Pesticide Programs Division Director. Washington (DC): US Environmental Protection Agency; 1991.

43. US Public Health Service. Hazardous substance data bank. Washington (DC): US Public Health Service; 1995.

44. Edwards IR, Ferry DG, Temple WA. Fungicides and related compounds. In: Hayes WJ, Laws ER. Handbook of pesticide toxicology. New York (NY): Academic Press; 1991.

45. Jablonicka A, Polakova H, Karelova J, Vargova M. Analysis of chromosome aberrations and sister-chromatid exchanges in peripheral blood lymphocytes of workers with occupational exposure to the mancozeb-containing fungicides Novozir Mn80. Mutat Res. 1989;224:143-6.

46. US Environmental Protection Agency (US EPA). List of chemicals evaluated for carcinogenic potential. Washington (DC): US EPA, Office of Pesticide Programs; 1996.

47. US Environmental Protection Agency. Pesticide fact sheet number 125: mancozeb. Washington (DC): Office of Pesticides and Toxic Substances; 1987.

48. Rothman KJ. No adjustments are needed for multiple comparisons. Epidemiology. 1990;1:43-6.

49. Flower KB, Hoppin JA, Lynch CF, Blair A, Knott C, Shore DL, Sandler DP. Cancer risk and parental pesticide application in children of agricultural health study participants. Environ Health Perspect. 2004;112:631-5.

50. Kristensen P, Andersen A, Irgens LM, Bye AS, Sundeheim L. Cancer in offspring of parents engaged in agricultural activities in Norway: incidence and risk factors in the farm environment. Int J Cancer. 1996;65:39-50.

51. Reynolds P, Von Behren J, Gunier R, Goldberg D, Hertz A. Childhood cancer and agricultural pesticide use: an ecologic study in California. Environ Health Perspect. 2002;9:319-24.

52. VanSteensel-Mol HA, Valkenburg HA, Van Zanen GE. Childhood leukemia and parental occupation: a register-based casecontrol study. Am J Epidemiol. 1985;121:216-24.

Received for publication: 7 September 2006 